\title{
Incidence and predictors of new persistent opioid use following inflammatory bowel disease flares treated with oral corticosteroids
}

\author{
Mohamed Noureldin $^{1,2}$ | Peter D. R. Higgins ${ }^{1}$ | Shail M. Govani ${ }^{3}$ | Shirley Cohen- \\ Mekelburg $^{1}$ | Brooke C. Kenney ${ }^{4,5}$ | Ryan W. Stidham ${ }^{1}$ (D) | Jennifer F. Waljee ${ }^{4,5}$ | \\ Akbar K. Waljee ${ }^{1,2}$
}

${ }^{1}$ Department of Internal Medicine, Division of Gastroenterology and Hepatology, Michigan Medicine, University of Michigan, Ann Arbor, Michigan

${ }^{2}$ Veterans Affairs Center for Clinical Management Research, Ann Arbor, Michigan

${ }^{3}$ Department of Internal Medicine, Division of Gastroenterology, The University of Texas Health Science Center at San Antonio, San Antonio, Texas

${ }^{4}$ Department of Surgery, University of Michigan, Ann Arbor, Michigan

${ }^{5}$ Michigan Opioid Prescribing Engagement Network, University of Michigan, Ann Arbor, Michigan

\section{Correspondence}

Akbar K. Waljee, Division of

Gastroenterology, Department of Internal Medicine, Michigan Medicine, Ann Arbor

Veterans Affairs Medical Center, Ann Arbor, MI.

Email: awaljee@med.umich.edu

Funding information

National Institutes of Health, Grant/Award Number: NIH R01 GM097117; United States Department of Veterans Affairs Health Services Research and Development Service, Grant/Award Number: CDA 11-217, IIR 16-024

\section{Summary}

Background: Opioids are commonly prescribed to manage pain associated with inflammatory bowel disease (IBD). It is unknown what percentage of patients develop new persistent opioid use following a steroid-treated IBD flare.

Aim: To identify the incidence and the predictors of new persistent opioid use following an IBD flare.

Methods: We used a national insurance claim dataset to identify patients with IBD who received an opioid medication around the time of a corticosteroid-treated IBD flare. Patients were stratified as previously opioid naïve, intermittent users, or chronic users. The incidence of persistent opioid use among the opioid-naïve cohort was evaluated along with associated predictors.

Results: We identified 15119 IBD patients who received opioids around the time of a flare. 5411 (35.8\%) were opioid-naïve patients of which $35.0 \%$ developed persistent opioid use after the flare. Factors associated with new persistent opioid use include a history of depression (hazard ratio [HR] 1.29, 95\% confidence interval [Cl] 1.13-1.47), substance abuse ( $\mathrm{HR} 1.36,95 \% \mathrm{Cl} 1.2-1.54)$, chronic obstructive pulmonary disease (COPD) (HR 1.17, 95\% Cl 1.04-1.3), as well as, Crohn's disease (HR $1.26,95 \% \mathrm{Cl} 1.14-1.4$ ) or indeterminate colitis (HR 1.6, $95 \% \mathrm{Cl} 1.36-1.88$ ).

Conclusions: New persistent opioid use is common in IBD patients who experience a flare, especially among those with mental health disorders, COPD, and Crohn's disease or indeterminate colitis. These findings can be helpful in risk-stratifying patients when choosing an acute pain therapy and providing counselling before choosing to prescribe opioids to opioid-naïve patients experiencing an IBD flare. 


\section{INTRODUCTION}

The opioid epidemic related to prescription misuse has been a topic of recent intense scrutiny on a national level. ${ }^{1}$ The number of opioid prescriptions in the U.S. has increased by $35 \%$ between the years 2002 and 2009. ${ }^{2}$ Approximately 15.5 million adult Americans reported misusing prescription opioids, and 1.9 million met the diagnostic criteria for opioid prescription abuse. ${ }^{2}$ Death resulting from overdosing on a prescribed opioid is far greater than the number of fatal overdoses caused by cocaine and heroin combined. ${ }^{3-6}$ It has been shown that chronic opioid use is associated with many adverse events including an increased risk of myocardial infarction, bowel obstruction, respiratory distress, falls, and fractures. ${ }^{7-9}$

Inflammatory bowel disease (IBD) flares are characterized by symptoms of abdominal and pelvic pain and diarrhoea for which an opioid could be used for symptomatic relief. Rheumatologic extra-intestinal manifestations of IBD can be another aetiology of pain in this patient population. Pain associated with flares usually subsides following flare resolution; however, pain symptoms can persist in the absence of objective evidence of active disease. ${ }^{10,11}$ Worsening abdominal pain with continued or escalating doses of narcotics may manifest as narcotic bowel syndrome. ${ }^{11}$ It has been reported that IBD is an independent risk factor for using higher dosages of opioids. ${ }^{12}$ In fact, in England, there has been a $20 \%$ rise in opioid prescribing among IBD patients in the last 20 years. ${ }^{1}$

Persistence of opioid use in previously opioid-naïve patients has been studied in patients prescribed opioids following various types of surgery. New persistent opioid use has been associated with different patient factors including behavioural and pain disorders. ${ }^{13}$ In addition, appreciating the dangers of prescribing narcotics for patients with IBD is an important step in the prevention of narcotic misuse. ${ }^{10}$ The aims of this study were (a) to determine the incidence of new persistent opioid use following IBD flares treated with oral corticosteroids; and (b) to identify patient factors associated with new persistent opioid use among opioid-naïve patients.

\section{METHODS}

\section{1 | Design}

We performed a retrospective cohort analysis to identify the incidence of and associations with persistent opioid use following IBD flares treated with oral corticosteroid.

\section{2 | Data sources}

We queried the Marketscan databases (Truven Health Analytics) between 1 January 2009 and 31 December 2015 to identify patients with IBD diagnoses. The Marketscan databases contain health insurance claims of more than 230 million privately insured patients in the United States. The databases use rigorous methods to ensure that claims and enrolment data are complete, accurate, and reliable. ${ }^{13}$ The databases have been accurately used to evaluate health outcomes in various clinical settings. ${ }^{13}$ Within these databases we examined outpatient visits, inpatient admissions, services, enrolment tables, and pharmacy claims. Approval from the Institutional Review Board at the University of Michigan was obtained to evaluate the data (HUM00127665).

\section{3 | Study sample}

The International Classification of Diseases, Ninth Revision, Clinical Modification diagnosis codes were used to identify patients 18 years or older with a diagnosis of IBD (555.x and 556.x). For the case definition of IBD we required at least three IBD codes on three different visit encounters, ${ }^{14}$ or one IBD-related visit encounter associated with an IBD medication prescription (a 5-aminosalicylate, immunomodulator, or biologic), which were identified using National Drug Codes listed in pharmacy claims. ${ }^{15}$ An IBD flare was defined by a new prescription for an oral systemic corticosteroid for at least 14 days not preceded by oral steroid use within the 120 days prior as is consistent with previously published literature. ${ }^{16,17}$ The reliability of this algorithm has been verified before with survey data. ${ }^{16}$

We included patients who used an opioid around the time of the flare (within 30 days before or 14 days after the index flare). Only one index flare per patient was considered. Inclusion criteria required at least 12 months of continuous insurance enrolment before and after the index flare to accurately capture health comorbidities and outcome events. Patients were then classified prior to the index date into three groups: (a) chronic opioid users if they were prescribed at least 120 days of opioids within the year before the flare, or had received at least three opioid prescriptions within 90 days before the flare; (b) opioid-naïve users if they received no opioid prescriptions within the year preceding the flare; or (c) intermittent opioid users if they did not meet the criteria for chronic or naïve opioid users. Similar definitions have been previously used in the literature to categorize opioid users. ${ }^{13}$ The algorithm we used to select the study cohort is summarized in (Figure 1). A complete list of opioid medications, 5-aminosalicylates, immunomodulators, biologics, and corticosteroids can be found in Appendix 1.

\subsection{Outcomes}

We abstracted age, gender, Charlson comorbidities, in addition to mental health conditions which included history of anxiety, depression, substance abuse (including opioid-type dependence), and other mental health disorders (including delirium, delusions, bipolar, manic, personality, sexual, and adjustment disorders) over the year prior to the index flare. We used an established algorithm, developed by Quan et $a l,{ }^{18}$ to abstract Charlson comorbidities (cancer, cerebrovascular disease, congestive heart failure, chronic obstructive pulmonary disease, dementia, complicated diabetes mellitus, noncomplicated diabetes mellitus, human immunodeficiency virus, cancer with metastasis, myocardial infarction, mild liver disease, moderate or severe liver disease, hemiplegia, peptic ulcer disease, peripheral vascular disease, renal disease, and rheumatological disease). 


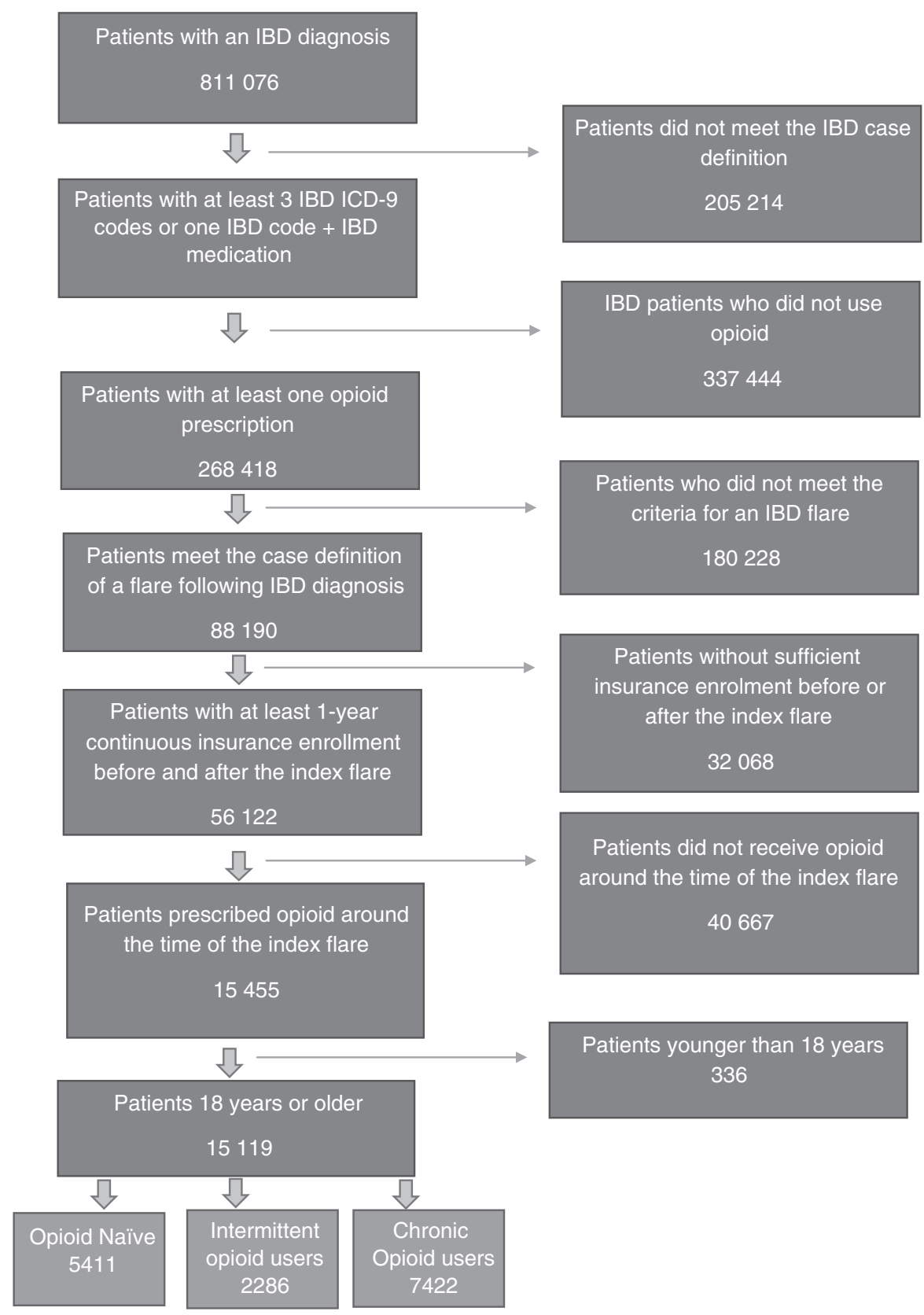

FIGURE 1 Patients selection algorithm

The type of IBD was also abstracted (Crohn's disease, ulcerative colitis, or indeterminate colitis); patients were labelled as indeterminate colitis if they had both Crohn's and ulcerative colitis billing codes. We also abstracted concomitant IBD medication use at the time of the flare; for this we required at least one prescription of the medication within 3 months before the index flare. The primary endpoint was the development of persistent opioid use in opioidnaïve patients which was defined as opioid prescribed 90-365 days following the index IBD flare. We also calculated the median oral morphine equivalent dose per day for these prescriptions. ${ }^{19}$

\section{5 | Statistical analysis}

Our analyses mainly focused on opioid naïve patients as they can be candidates for primary prevention strategies. Univariate unadjusted analyses were performed to compare demographics and baseline comorbidities between persistent and non-persistent opioid-naïve users. The Chi-square test and student $t$ test were used for categorical and normally distributed continuous variables, respectively. Independent predictors of persistent opioid use were identified using a Cox proportional hazard model accounting for the time to the event (time from index IBD flare to opioid persistence) while controlling for patient demographics and health comorbidities. Variables were selected for inclusion in the Cox model if they were statistically significant or approaching statistical significance $(P \leq 0.1)$ in univariate analyses. To mitigate the impact of subsequent IBD flares (after the index flare) in estimating the hazard ratios for persistent opioid use, we incorporated subsequent flares as a time varying covariate in the model; this approach is known for improving the model's goodness of fit. ${ }^{20}$ Patients were censored at 365 days following the index 
flare. A two-sided $P$ value, with false discovery rate adjustment, $\leq 0.05$ was used to determine statistical significance. All analyses were performed using SAS software (version 9.4, SAS Institute Inc., Cary, NC, USA)

In sensitivity analyses for persistent opioid use in naive patients; we rebuilt the Cox model after excluding patients who underwent IBD-related surgery (Appendix 2) or were hospitalized within the first 90 days following the index flare to remove possible confounding by indication (ie, opioid prescribed following IBD surgery or hospitalization rather than IBD flare), and that patients who required surgery or hospitalization following the index flare might have had a more severe disease that required extended period of opioid use which may further inflate the rate of opioid persistence. In a third sensitivity analysis we created a cohort of pooled opioid-naïve and intermittent opioid users to examine the independent association of previous intermittent opioid use with opioid persistence following an IBD flare. In a fourth sensitivity analysis, we examined the rate of opioid persistence after excluding patients who underwent surgical procedure codes for anaesthesia between 90 and 365 days after the index flare as they may have received opioid prescriptions for an acutely limited problem. ${ }^{13}$ Likewise, we also examined persistence after excluding patients with multiple IBD flares other than the index flare. We also examined alternative definitions for opioid persistence as reported in the literature including (a) any opioid prescription 90-180 days following the index flare ${ }^{13}$; and (b) an opioid prescription 205-425 days following the index flare. ${ }^{21}$ Lastly, we identified those who were prescribed at least $50 \mathrm{mg}$ of oral morphine or equivalent anytime 90-365 days following the index flare; in this approach we accounted for overlapping prescriptions and calculated sums of oral morphine equivalents across prescribed days. This approach has been shown to improve identification of patients at high-risk of overdosing. ${ }^{22}$

\section{RESULTS}

Between 2009 and 2015, we identified a total of 605862 patients with IBD of whom 44.3\% (268 418) received an opioid prescription during the study period. 15119 patients met the inclusion criteria and used opioids around the time of the index flare (Figure 1). Of those, $49.1 \%(n=7422)$ were chronic opioid users, $15.1 \%$ $(n=2286)$ were intermittent opioid users, and 35.8\% ( $n=5411)$ were opioid-naïve patients. The average ages ( \pm standard deviation) for chronic, intermittent, and naive opioid users were $50.6( \pm 14.7)$, $45.4( \pm 15.3)$, and $43.9( \pm 15.8)$, respectively. Females represented 63.5\% ( $n=4716), 61.3 \%(n=1402)$, and $54.3 \%(n=2939)$ of these cohorts, respectively (Table 1 ).

Among opioid-naïve IBD patients, the risk of developing new persistent opioid use is $35.0 \%(n=1893)$ following an IBD flare that required a steroid prescription. The persistence rates in the intermittent and chronic opioid users were $49.4 \%$, and $73.7 \%$, respectively. The median oral morphine equivalent/day for opioid naïve patients who persisted, accounting for overlapping prescriptions, was $72.0 \mathrm{mg}$ (IQR: 60.0-90.0 mg). In univariate analyses, the opioid-naive patients
TABLE 1 Opioid users around the initial IBD flare by type

\begin{tabular}{llll} 
& \multicolumn{3}{l}{ Opioid user by type } \\
\cline { 2 - 4 } Variable & Chronic & Intermittent & Naive \\
\hline Total $(\%)$ & $7422(49.1)$ & $2286(15.1)$ & $5411(35.8)$ \\
Females $(\%)$ & $4716(63.5)$ & $1402(61.3)$ & $2939(54.3)$ \\
\hline Age $($ mean \pm SD) & $50.6( \pm 14.7)$ & $45.4( \pm 15.3)$ & $43.9( \pm 15.8)$ \\
\hline
\end{tabular}

$\mathrm{SD}$, standard deviation.

most likely to become persistent opioid users after a flare were more likely to have a history of chronic obstructive pulmonary disease, noncomplicated diabetes mellitus, a rheumatological disease, or a mental health disorder including anxiety, depression, and substance abuse. The median (IQR) Charlson comorbidity index in both cohorts was 0 (0-2). Patients with Crohn's disease, indeterminate colitis, and those on biologics were also more likely to become persistent opioid users. In contrast, patients on 5-aminosalicylate medications were less likely to become persistent opioid users $(P<0.05)$ (Table 2).

In multivariable analysis, the independent predictors of new persistent opioid use are a history of depression (hazards ratio [HR] 1.29, $95 \% \mathrm{Cl} 1.13-1.47)$, substance abuse ( $\mathrm{HR} 1.36,95 \% \mathrm{Cl} 1.20-$ 1.54), chronic obstructive pulmonary disease (HR 1.17, 95\% Cl 1.041.30), as well as Crohn's disease ( $\mathrm{HR} 1.26,95 \% \mathrm{Cl} 1.14-1.40)$ and indeterminate colitis ( $\mathrm{HR} 1.60,95 \% \mathrm{Cl}$ 1.36-1.88) compared with ulcerative colitis. 5 -aminosalicylate use at the time of the flare was protective against opioid persistence (Table 3 ).

In a sensitivity analysis excluding patients with a hospitalization or IBD-related surgery occurring in the first 90 days following the index flare $(n=1034)$, persistent opioid users represented $32.7 \%(n=1433)$ of 4377 opioid naïve users. Independent predictors of persistent opioid use remained similar to the findings of the primary analysis other than 5-aminosalicylates which was no longer a predictor (Appendix 3). When opioid naïve and intermittent opioid users were pooled together, prior intermittent opioid use was an independent predictor of future opioid persistence following an IBD flare (HR 1.51, 95\% Cl 1.40-1.63) (Appendix 4). When we excluded patients who underwent surgery between 90-365 days following the index flare $(n=1253)$, the persistence rate for opioid naïve patients was $25.4 \%$. After excluding patients who developed multiple flares other than the index flare ( $n=402$ ), persisted opioid users represented $35.9 \%$ of the opioid naïve patients (compared to $35.8 \%$ without excluding these patients). Examining the alternative definitions of opioid persistence (opioid prescribed $90-180$ and $205-425$ after the index flare) revealed that $22.8 \%$ ( $n=1235)$ and $16.7 \%(n=906)$ of opioid naïve patients persisted, respectively. We also found that $18.8 \%(n=1015)$ of opioid naïve patients used at least one prescription of $50 \mathrm{mg}$ of oral morphine equivalents or more 90-365 days following the index flare.

\section{DISCUSSION}

This is the first study to examine the risk of developing new persistent opioid use in IBD patients. Among a United States cohort of 
TABLE 2 Univariate comparison between persistent and nonpersistent opioid users among opioid naïve patients

\begin{tabular}{|c|c|c|c|}
\hline Variable & $\begin{array}{l}\text { Persisted } \\
\text { opioid users }\end{array}$ & $\begin{array}{l}\text { Non- } \\
\text { persisted } \\
\text { users }\end{array}$ & $\begin{array}{l}\text { Adjusted } \\
\text { P-value }^{a}\end{array}$ \\
\hline \multicolumn{4}{|l|}{ Demographics } \\
\hline Total (\%) & $1893(35.0)$ & $3518(65.0)$ & - \\
\hline Age, mean (SD) & $44.0(15.6)$ & $43.9(16.0)$ & 0.88 \\
\hline Female & $1060(56.1)$ & $1867(53.3)$ & 0.15 \\
\hline Region & & & 0.16 \\
\hline Northeast & $350(18.5)$ & $686(19.5)$ & \\
\hline Northcentral & $436(23)$ & $882(25.1)$ & \\
\hline South & 737 (38.9) & $1283(36.5)$ & \\
\hline West & 312 (16.5) & $586(16.7)$ & \\
\hline Unknown & $58(3.1)$ & $81(2.3)$ & \\
\hline
\end{tabular}

\begin{tabular}{|c|c|c|c|}
\hline \multicolumn{4}{|l|}{ Type of ID disease } \\
\hline Crohn's & $1137(60.1)$ & $1939(55.1)$ & 0.02 \\
\hline Ulcerative colitis & $558(29.5)$ & $1320(37.5)$ & \\
\hline Indeterminate colitis & $198(10.5)$ & $259(7.4)$ & \\
\hline \multicolumn{4}{|l|}{ Comorbidities } \\
\hline Cancer & $173(9.1)$ & $292(8.3)$ & 0.36 \\
\hline $\begin{array}{l}\text { Cerebrovascular } \\
\text { disease }\end{array}$ & $122(6.4)$ & $194(5.5)$ & 0.22 \\
\hline $\begin{array}{l}\text { Congestive heart } \\
\text { failure }\end{array}$ & $95(5)$ & $136(3.9)$ & 0.10 \\
\hline $\begin{array}{l}\text { Chronic obstructive } \\
\text { pulmonary disease }\end{array}$ & $438(23.1)$ & $665(18.9)$ & 0.02 \\
\hline Dementia & $6(0.3)$ & $12(0.3)$ & 0.90 \\
\hline $\begin{array}{l}\text { Complicated diabetes } \\
\text { mellitus }\end{array}$ & $45(2.4)$ & $71(2)$ & 0.44 \\
\hline $\begin{array}{l}\text { Non-complicated } \\
\text { diabetes mellitus }\end{array}$ & $215(11.4)$ & $329(9.4)$ & 0.05 \\
\hline $\begin{array}{l}\text { Human } \\
\text { immunodeficiency } \\
\text { virus }\end{array}$ & $5(0.3)$ & $7(0.2)$ & 0.71 \\
\hline Cancer with metastasis & $45(2.4)$ & $80(2.3)$ & 0.88 \\
\hline Myocardial infarction & $43(2.3)$ & $54(1.5)$ & 0.10 \\
\hline Mild liver disease & $216(11.4)$ & $395(11.2)$ & 0.89 \\
\hline $\begin{array}{l}\text { Moderate or severe } \\
\text { liver disease }\end{array}$ & $22(1.2)$ & $51(1.4)$ & 0.44 \\
\hline Hemiplegia & $15(0.8)$ & $14(0.4)$ & 0.11 \\
\hline Peptic ulcer disease & $59(3.1)$ & $123(3.5)$ & 0.52 \\
\hline $\begin{array}{l}\text { Peripheral vascular } \\
\text { disease }\end{array}$ & $141(7.4)$ & $219(6.2)$ & 0.14 \\
\hline Renal disease & $78(4.1)$ & $121(3.4)$ & 0.27 \\
\hline $\begin{array}{l}\text { Rheumatological } \\
\text { disease }\end{array}$ & $120(6.3)$ & $168(4.8)$ & 0.03 \\
\hline \multicolumn{4}{|l|}{ Mental health disorders } \\
\hline Anxiety & $416(22)$ & 599 (17) & 0.02 \\
\hline Depression & 311 (16.4) & 377 (10.7) & 0.02 \\
\hline Substance abuse & 311 (16.4) & 384 (10.9) & 0.02 \\
\hline
\end{tabular}

(Continues)
TABLE 2 (Continued)

\begin{tabular}{|cccl|}
\hline Variable & $\begin{array}{l}\text { Persisted } \\
\text { opioid users }\end{array}$ & $\begin{array}{l}\text { Non- } \\
\text { persisted } \\
\text { users }\end{array}$ & $\begin{array}{l}\text { Adjusted } \\
\text { P-value }^{\text {a }}\end{array}$ \\
\hline Other mental disorders & $172(9.1)$ & $236(6.7)$ & 0.02 \\
\hline IBD related medications & & & \\
\hline 5-Acetylsalicylic acid & $598(31.6)$ & $1283(36.5)$ & 0.02 \\
\hline Immunomodulators & $93(4.9)$ & $169(4.8)$ & 0.90 \\
\hline Biologics & $81(4.3)$ & $108(3.1)$ & 0.05 \\
\hline Budesonide & $15(0.8)$ & $26(0.7)$ & 0.89 \\
\hline
\end{tabular}

$\mathrm{SD}$, standard deviation.

${ }^{a}$ False discovery rate (FDR) adjusted $P$ values.

TABLE 3 Survival model for predictors of persistent opioid users among opioid naïve patients

\begin{tabular}{lll} 
Predictors & $\begin{array}{l}\text { Hazard ratio (95\% } \\
\text { Cl) }\end{array}$ & $\begin{array}{l}\text { P- } \\
\text { value }^{\mathrm{b}}\end{array}$ \\
\hline $\begin{array}{l}\text { Depression } \\
\text { Substance abuse }\end{array}$ & $1.29(1.13-1.47)$ & 0.02 \\
\hline $\begin{array}{l}\text { Chronic obstructive pulmonary } \\
\text { disease }\end{array}$ & $1.17(1.20-1.54)$ & 0.02 \\
\hline Crohn's disease vs UC & $1.26(1.14-1.4)$ & 0.03 \\
\hline Indeterminate colitis vs UC & $1.60(1.36-1.88)$ & 0.02 \\
\hline 5-aminosalicylate use & $0.88(0.80-0.97)$ & 0.02 \\
\hline Subsequent flares & \\
\hline Anxiety & $3.85(2.79-5.32)$ & 0.02 \\
\hline Other mental health disorders & $1.12(1.00-1.26)$ & 0.11 \\
\hline Non-complicated diabetes mellitus & $1.16(0.99-1.37)$ & 0.12 \\
\hline Rheumatological disease & $1.14(0.98-1.32)$ & 0.13 \\
\hline Myocardial infarction & $1.17(0.97-1.42)$ & 0.14 \\
\hline Congestive heart failure & $1.21(0.89-1.66)$ & 0.30 \\
\hline Biologic use & $1.11(0.89-1.39)$ & 0.42 \\
\hline
\end{tabular}

UC, ulcerative colitis.

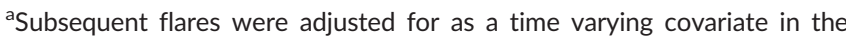
survival model.

${ }^{b}$ False discovery rate (FDR) adjusted $P$ values.

15119 patients who used opioids around the time of an IBD flare, $35.8 \%$ were opioid-naïve patients. Of the opioid-naïve users, more than one-third (35.0\%) became persistent opioid users. This is an important finding because it highlights the significance and the magnitude of new persistent opioid use as an underappreciated iatrogenic complication following an IBD flare. More than half of these patients ( $n=1015 ; 53.6 \%$ ) used at least one prescription of $50 \mathrm{mg}$ of oral morphine equivalents or more which has been previously shown to be associated with 3.7 to 8.9 -fold increase in overdose risk. $^{23}$

This new data is complimentary to currently available literature on opioids in IBD. It has been well established that the prevalence of opioid use in IBD is rising, as it is the general United States population. ${ }^{24}$ In a landmark paper, Targownik, et al investigated heavy opioid use in IBD patients and reported that individuals with IBD are 
3 times more likely to become heavy opioid users compared with their matched controls. Heavy opioid use was also significantly associated with mortality. ${ }^{12}$ Hence, this is an essential topic to address proactively in IBD care.

We also demonstrated that the predictors of new persistent opioid use include a history of depression, substance abuse, and chronic obstructive pulmonary disease. Patients with IBD and chronic obstructive pulmonary disease are at a particularly high risk for complications from opioid use. A recent study demonstrated a higher mortality among chronic obstructive pulmonary disease patients who use opioids. ${ }^{25}$ These predictors are also similar to a great extent with previous surgical literature evaluating predictors of new persistent opioid use following surgical procedures. ${ }^{13}$ Mental health disorders are also known predictors of opioid use and misuse. ${ }^{10} \mathrm{~A}$ recent study of Veterans with structural and unexplained gastrointestinal symptoms also identified the higher likelihood of opioid prescriptions among patients with comorbid psychiatric disease. ${ }^{26}$ Substance abuse and other mental health disorders often co-exist. The link is likely multifactorial, though theories correlating among these disorders include substance abuse disorder related psychiatric symptoms and substance abuse as a result of self-medicating. ${ }^{27}$ Further, it's important to note that there is a known association between psychiatric disease and active IBD, which could potentially increase the likelihood of opioid seeking behaviour. ${ }^{28}$

Persistent opioid use was also independently associated with Crohn's disease and indeterminate colitis compared with ulcerative colitis. The pain-predominant symptoms impacting patients with Crohn's disease as compared to ulcerative colitis likely contributes to this association. Additionally, patients on a 5-aminosalicylate medication were less likely to become persistent opioid users. This association could be driven by the increased use of 5-aminosalicylates in ulcerative colitis and the milder severity of the underlying IBD disease in patients on a 5-aminosalicylate compared to patients using immunomodulators or biologics. A previous case-control study identifying factors associated with opioid use in IBD patients showed similar associations such as depression, anxiety, and substance abuse. ${ }^{29}$ These findings can be helpful in risk stratifying patients, weighing analgesic choices and alternatives, and providing counselling for opioid naïve patients when choosing an acute pain therapy for an IBD flare.

Management strategies for chronic pain are a primary focus in the midst of the opioid epidemic. ${ }^{18,30-32}$ However, no clear consensus on guidelines regarding acute pain management surrounding an IBD flare have been investigated. A recent study showed that IBD patients are more likely to be prescribed narcotics in acute care settings such as emergency departments, urgent care settings, and surgical outpatient follow up visits. ${ }^{33}$ Alternatives to opioids need to be considered in the management of pain related to IBD, including neuroleptic medications and psychotherapy. ${ }^{34,35}$ As such, further studies exploring the management of acute pain in IBD patients are warranted to address this need.

The limitations of this study are inherent to any large administrative databases; while these databases excel in evaluating global trends and patterns, they lack granularity. For instance, we were not able to determine the severity of IBD in each patient and stratify the patients accordingly. Likewise, other disease related issues such as anatomical location, perianal disease, age at onset, and tobacco use cannot be accurately measured in an administrative database. We are not able to further characterize opioid prescribers' specialty, institutional factors, such as differentiating urban and rural settings, or account for opioid diversion. Databases are subject to data entry errors which may lead to inaccurate billing codes. The Marketscan databases use rigorous methods to ensure that claims and enrolment data are complete, accurate, and reliable. ${ }^{13}$ The databases have been accurately used to evaluate health outcomes in various clinical settings. ${ }^{13}$

Persistent opioid use might have resulted from other factors such as IBD-related surgeries leading to extended opioid requirements. ${ }^{36}$ To address this issue, in a sensitivity analysis, we excluded patients who underwent IBD-related surgeries around the index flare (090 days). We found no major difference in the incidence of persistent opioid use or identified predictors. While we acknowledge the myriad of treatment options available for treating IBD flares including biologics, immunomodulators, and parenteral steroid use, we only investigated patients who were treated with oral steroids for an IBD flare as consistent with previously published literature ${ }^{16}$ for the simplicity of approach. Indeed, a recent study demonstrated that despite the availability of new multiple treatment options for IBD disease, the utilization of corticosteroids has remained constant with no decline through the years 2003-2011. ${ }^{33}$ In our analyses, we also controlled for the concomitant use of these agents at the time of the flare. It is uncertain whether the findings of this study are generalizable to patients treated for flares without oral corticosteroids. Likewise, as the population of this study is based on commercial insurance databases, the findings of this study are not necessarily generalizable to the uninsured, underinsured, or the general Medicare population.

Despite these limitations, this study of 15119 privately insured patients in the United States with opioid use around the time of steroid-defined flares underscores the significance of persistent opioid use following an IBD flare as an underappreciated iatrogenic complication. The study also identifies several patient factors associated with high risk of persistent opioid use.

In conclusion, new persistent opioid use is common in the United States following an IBD flare treated with corticosteroids. Persistent opioid use is increased among those with mental health disorders, chronic obstructive pulmonary disease, prior opioid use, and Crohn's disease or indeterminate colitis, compared with ulcerative colitis. These findings can be helpful in risk-stratifying patients when choosing an acute pain therapy and guiding counselling of patients before prescribing opioids to opioid-naïve patients experiencing an IBD flare. Further studies are warranted to investigate the physician-level and health-system level risk factors associated with new persistent opioid use.

\section{ACKNOWLEDGEMENTS}

Declaration of personal interests: Peter D. R. Higgins has served as a consultant for Takeda Pharmaceuticals International, Inc. $\mathrm{PH}$ has 
served as a speaker for the GI Health Foundation and PRIME Medical Education, a consultant and an advisory board member for AbbVie, Allergan, Amgen, Eli Lilly, Janssen, Lycera, Takeda, UCB and has received research funding from AbbVie, Amgen, Arena, Ascentage Pharma, BCBS of Michigan, Buhlmann, Eli Lilly, Genentech, Janssen, Lycera, Medimmune, Nestle, Pfizer, RedX Pharma, Seres, Shire, Takeda, and UCB. All other authors have no personal interests to declare.

Declarations of funding interests: Akbar K. Waljee was supported by a career development grant award (CDA 11-217) and a Merit Review Award Number (IIR 16-024) from the United States Department of Veterans Affairs Health Services Research and Development Service. Peter D.R. Higgin's and Akbar K. Waljee's research is supported by NIH R01 GM097117. The content is solely the responsibility of the authors and does not necessarily represent the official views of the University of Michigan, the Veterans Affairs, or the National Institutes of Health.

\section{AUTHORSHIP}

Guarantor of the article: Akbar K. Waljee the submission's guarantor, takes responsibility for the integrity of the work as a whole, from inception to published article.

Author contributions: Mohamed Noureldin, concept and design, data analysis and interpretation, writing, figures, critical revision of the manuscript, final approval; Peter D. R. Higgins, data interpretation, writing, critical revision of the manuscript, final approval; Shail M. Govani, data interpretation, critical revision of the manuscript, final approval; Shirley Cohen-Mekelburg, data interpretation, critical revision of the manuscript, final approval; Brooke C. Kenney critical revision of the manuscript, final approval; Ryan W. Stidham, data interpretation, writing, critical revision of the manuscript, final approval; Jennifer F. Waljee, critical revision of the manuscript, final approval; Akbar K. Waljee, Concept and design, data analysis and interpretation, writing, figures, critical revision of the manuscript, final approval. All authors approved the final version of the manuscript.

\section{ORCID}

Ryan W. Stidham iD http://orcid.org/0000-0001-9638-2186

Akbar K. Waljee iD http://orcid.org/0000-0003-1964-8790

\section{REFERENCES}

1. Burr NE, Smith C, West R, Hull MA, Subramanian V. Increasing prescription of opiates and mortality in patients with inflammatory bowel diseases in England. Clin Gastroenterol Hepatol. 2018;16:534541.e6.

2. Lan PX, Lee JW, Seol Y-J, Cho D-W. Development of 3D PPF/DEF scaffolds using micro-stereolithography and surface modification. $J$ Mater Sci Mater Med. 2008;20:271-279.
3. Wright EA, Katz JN, Abrams S, Solomon DH, Losina E. Trends in prescription of opioids from 2003-2009 in persons with knee osteoarthritis. Arthritis Care Res (Hoboken). 2014;66:1489-1495.

4. Paulozzi LJ, Mack KA, Hockenberry JM. Variation among states in prescribing of opioid pain relievers and benzodiazepines-United States, 2012. J Safety Res. 2014;51:125-129.

5. Paulozzi LJ, Weisler RH, Patkar AA. A national epidemic of unintentional prescription opioid overdose deaths: how physicians can help control it. J Clin Psychiatry. 2011;72:589-592.

6. Kenan K, Mack K, Paulozzi L. Trends in prescriptions for oxycodone and other commonly used opioids in the United States, 2000-2010. Open Med. 2012;6:e41-e47.

7. Von Korff M, Kolodny A, Deyo RA, Chou R. Long-term opioid therapy reconsidered. Ann Intern Med. 2011;155:325-328.

8. Solomon DH, Rassen JA, Glynn RJ, Lee J, Levin R, Schneeweiss S. The comparative safety of analgesics in older adults with arthritis. Arch Intern Med. 2010;170:1968-1976.

9. Aparasu RR, Chatterjee S. Use of narcotic analgesics associated with increased falls and fractures in elderly patients with osteoarthritis. Evid Based Med. 2014;19:37-38.

10. Edwards JT, Radford-Smith GL, Florin TH. Chronic narcotic use in inflammatory bowel disease patients: prevalence and clinical characteristics. J Gastroenterol Hepatol. 2001;16:1235-1238.

11. Grunkemeier DM, Cassara JE, Dalton CB, Drossman DA. The narcotic bowel syndrome: clinical features, pathophysiology, and management. Clin Gastroenterol Hepatol. 2007;5:1126-1139; quiz 1121 2.

12. Targownik LE, Nugent Z, Singh H, Bugden S, Bernstein CN. The prevalence and predictors of opioid use in inflammatory bowel disease: a population-based analysis. Am J Gastroenterol. 2014;109:1613.

13. Brummett CM, Waljee JF, Goesling J, et al. New persistent opioid use after minor and major surgical procedures in US adults. JAMA. 2017;152:e170504.

14. Grasberger H, Noureldin M, Kao TD, et al. Increased risk for inflammatory bowel disease in congenital hypothyroidism supports the existence of a shared susceptibility factor. Sci Rep. 2018;8:10158.

15. Crockett SD, Schectman R, Stürmer T, Kappelman MD. Topiramate use does not reduce flares of inflammatory bowel disease. Dig Dis Sci. 2014;59:1535-1543.

16. Lewis JD, Aberra FN, Lichtenstein GR, Bilker WB, Brensinger C, Strom BL. Seasonal variation in flares of inflammatory bowel disease. Gastroenterology. 2004;126:665-673.

17. Crockett SD, Hansen RA, Stürmer T, et al. Statins are associated with reduced use of steroids in inflammatory bowel disease: a retrospective cohort study. Inflamm Bowel Dis. 2012;18:1048-1056.

18. Quan H, Sundararajan V, Halfon $P$, et al. Coding algorithms for defining comorbidities in ICD-9-CM and ICD-10 administrative data. Med Care. 2005;43:1130-1139.

19. Nielsen S, Degenhardt L, Hoban B, Gisev N. A synthesis of oral morphine equivalents (OME) for opioid utilisation studies. Pharmacoepidemiol Drug Saf. 2016;25:733-737.

20. Moolgavkar SH, Chang ET, Watson HN, Lau EC. An assessment of the cox proportional hazards regression model for epidemiologic studies. Risk Anal. 2017;38:777-794.

21. Alam A, Gomes T, Zheng H, Mamdani MM, Juurlink DN, Bell CM. Long-term analgesic use after low-risk surgery: a retrospective cohort study. Arch Intern Med. 2012;172:425-430.

22. Yang Z, Wilsey B, Bohm M, et al. Defining risk of prescription opioid overdose: pharmacy shopping and overlapping prescriptions among long-term opioid users in medicaid. J Pain. 2015;16:445-453.

23. Dunn KM, Saunders KW, Rutter CM, et al. Opioid prescriptions for chronic pain and overdose: a cohort study. Ann Intern Med. 2010;152:85-92.

24. Wren AA, Bensen R, Sceats L, et al. Starting Young: trends in opioid therapy among US adolescents and young adults with inflammatory 
bowel disease in the Truven MarketScan Database Between 2007 and 2015. Inflamm Bowel Dis. 2018;24:2093-2103.

25. Vozoris NT, Wang X, Fischer HD, et al. Incident opioid drug use among older adults with chronic obstructive pulmonary disease: a population-based cohort study. Br J Clin Pharmacol. 2016;81:161170.

26. Sayuk GS, Kanuri N, Gyawali CP, Gott BM, Nix BD, Rosenheck RA. Opioid medication use in patients with gastrointestinal diagnoses vs unexplained gastrointestinal symptoms in the US Veterans Health Administration. Aliment Pharmacol Ther. 2018;47:784-791.

27. Kingston REF, Marel C, Mills KL. A systematic review of the prevalence of comorbid mental health disorders in people presenting for substance use treatment in Australia. Drug Alcohol Rev. 2017;36:527-539.

28. van den Brink G, Stapersma L, Vlug LE, et al. Clinical disease activity is associated with anxiety and depressive symptoms in adolescents and young adults with inflammatory bowel disease. Aliment Pharmacol Ther. 2018;48:358-369.

29. Hanson KA, Loftus EV Jr, Harmsen WS, Diehl NN, Zinsmeister AR, Sandborn WJ. Clinical features and outcome of patients with inflammatory bowel disease who use narcotics: a case-control study. Inflamm Bowel Dis. 2009;15:772-777.

30. McCarthy M. Opioids should be last resort to treat chronic pain, says draft CDC guideline. BMJ. 2015;351:h6905.

31. Dowell D, Haegerich TM, Chou R. CDC guideline for prescribing opioids for chronic pain-United States, 2016. JAMA. 2016;315:1624 1645.
32. Frieden TR, Houry D. Reducing the risks of relief-the CDC opioidprescribing guideline. N Engl J Med. 2016;374:1501-1504.

33. Narula N, Borges L, Steinhart AH, Colombel JF. Trends in narcotic and corticosteroid prescriptions in patients with inflammatory bowel disease in the United States Ambulatory Care Setting from 2003 to 2011. Inflamm Bowel Dis. 2017;23:868-874.

34. Docherty MJ, Jones RCW, Wallace MS. Managing pain in inflammatory bowel disease. Gastroenterol Hepatol. 2011;7:592-601.

35. Srinath Al, Walter C, Newara MC, Szigethy EM. Pain management in patients with inflammatory bowel disease: insights for the clinician. Ther Adv Gastroenterol. 2012;5:339-357.

36. Gajendran M, Watson AR, Bauer AJ, et al. 927 End to end VS side to side anastomosis and post-operative Crohn's disease quality of life and healthcare utilization: a prospective comparative effectiveness study. Gastroenterology. 2015;148:S-177.

How to cite this article: Noureldin M, Higgins PDR, Govani $\mathrm{SM}$, et al. Incidence and predictors of new persistent opioid use following inflammatory bowel disease flares treated with oral corticosteroids. Aliment Pharmacol Ther. 2019;49:74-83. https://doi.org/10.1111/apt.15023

\section{APPENDIX 1}

List of medications abstracted

$\begin{array}{lll}\text { IBD related medications } & \text { Oral systemic steroids } & \text { Opioids } \\ \text { 5-ASA } & \text { Betamethasone } & \text { Butorphanol } \\ \text { Mesalamine } & \text { Dexamethasone } & \text { Buprenorphine } \\ \text { Olsalazine } & \text { Methylprednisolone } & \text { Methadone } \\ \text { Balsalazide } & \text { Triamcinolone } & \text { Hydrocodone } \\ \text { Sulfasalazine } & \text { Prednisone } & \text { Oxycodone } \\ \text { Immunomodulator } & \text { Prednisolone } & \text { Tramadol } \\ \text { Methotrexate } & \text { Hydrocortisone } & \text { Codeine } \\ \text { Cyclosporine } & \text { Cortisone } & \text { Hydromorphone } \\ \text { Azathioprine } & & \text { Meperidine } \\ \text { Mercaptopurine } & & \text { Morphine } \\ \text { Biologics } & & \text { Fentanyl } \\ \text { Infliximab } & & \text { Dihydrocodeine } \\ \text { Adalimumab } & & \text { Pentazocine } \\ \text { Certolizumab } & & \text { Oxymorphone } \\ \text { Natalizumab } & & \text { Tapentadol } \\ \text { Vedolizumab } & & \text { Levorphanol } \\ \text { Ustekinumab } & & \text { Propoxyphene } \\ \text { Golimumab } & & \\ \text { Non-systemic steroid } & & \\ \text { Budesonide } & & \end{array}$




\section{APPENDIX 2}

List of IBD related surgeries and corresponding codes

$\begin{array}{lll}\text { Procedure name } & \text { ICD9-CM procedure code } & \text { Corresponding CPT codes } \\ \text { Small intestinal resection } & 45.6-45.62 & 44157,44158,44211,45113,44141,44143,44144,44150,44206,44210, \\ \text { Colonic resection } & 45.71-45.76,45.79,45.8 & 44155,44212,44146,44140,44160,44204,44205,44145,44120,44125, \\ \text { Small intestinal fistula closure } & 46.74 & 44202,37197,45110,45111,45112,45114,45119,45123,45136,44320, \\ \text { Large intestinal fistula closure } & 46.76 & 45000,45005,45020,46040,46045,45800,45820,46030,57305,57308, \\ \text { Rectal surgery } & 48.49,48.5,48.61-48.65,48.69 & 46060,46706,46020 \\ \text { Rectal fistula closure } & 48.73 & \\ \text { Perirectal fistula closure } & 48.93 & \\ \text { Perianal abscess drainage } & 49.01 & \\ \text { Anal fistula repair } & 49.11-49.12,49.73 & \\ \text { Repair of fistula between } & 57.83,58.43 & \\ \text { intestines and urinary system } & & \\ \text { Repair of fistula between } & 70.72-70.74 & \\ \text { intestines and vagina } & \end{array}$

\section{APPENDIX 3}

Sensitivity analysis_-Survival model for predictors of persistent opioid users among opioid naïve patients excluding patients with hospitalizations or IBD related surgeries ${ }^{a}$

\begin{tabular}{lll}
\hline Predictors & Hazard ratio (95\% Cl) & Adjusted P-value $^{c}$ \\
\hline Depression & $1.40(1.21-1.63)$ & 0.02 \\
\hline Substance abuse & $1.42(1.23-1.64)$ & 0.02 \\
\hline Chronic obstructive pulmonary disease & $1.19(1.05-1.35)$ & 0.03 \\
\hline Crohn's vs UC & $1.32(1.17-1.48)$ & 0.02 \\
\hline Indeterminate Colitis vs UC & $1.52(1.24-1.86)$ & 0.02 \\
\hline Subsequent flares ${ }^{b}$ & $3.75(2.63-5.35)$ & 0.02 \\
\hline Rheumatological disease & $1.26(1.03-1.55)$ & 0.07 \\
\hline 5-ASA use & $0.89(0.80-1.00)$ & 0.09 \\
\hline Anxiety & $1.13(0.99-1.29)$ & 0.12 \\
\hline Non-complicated diabetes mellitus & $1.15(0.97-1.37)$ & 0.15 \\
\hline Myocardial Infarction & $1.32(0.91-1.91)$ & 0.20 \\
\hline Other mental health disorders & $1.13(0.93-1.37)$ & 0.28 \\
\hline Gender & $1.07(0.96-1.19)$ & 0.32 \\
\hline Cerebrovascular disease & $1.13(0.92-1.40)$ & 0.32 \\
\hline
\end{tabular}

UC, ulcerative colitis; 5-ASA, 5-Acetylsalicylic acid.

aExcluding patients with hospitalizations or surgeries 1-90 d following the index flare.

${ }^{b}$ Subsequent flares were adjusted for as a time varying covariate in the survival model.

${ }^{\mathrm{c}}$ False discovery rate (FDR) adjusted $P$-value. 


\section{APPENDIX 4}

Predictors of persistent opioid use in a pooled cohort of naïve and intermittent users

\begin{tabular}{|c|c|c|c|c|}
\hline Variable & Hazard ratio & \multicolumn{2}{|c|}{$\begin{array}{l}\text { 95\% Hazard ratio confidence } \\
\text { limits }\end{array}$} & \multirow{2}{*}{$\begin{array}{l}P \text {-values }{ }^{a} \\
0.09\end{array}$} \\
\hline Depression & 1.115 & 1.004 & 1.238 & \\
\hline Substance abuse & 1.251 & 1.134 & 1.379 & 0.02 \\
\hline Hemiplegia & 1.598 & 1.111 & 2.297 & 0.03 \\
\hline Indeterminate vs ulcerative colitis & 1.442 & 1.263 & 1.646 & 0.02 \\
\hline Crohn's vs ulcerative colitis & 1.190 & 1.097 & 1.292 & 0.02 \\
\hline DM, non-complicated & 1.138 & 1.017 & 1.275 & 0.06 \\
\hline Rheumatological disease & 1.167 & 1.015 & 1.341 & 0.07 \\
\hline 5-ASA & 0.914 & 0.844 & 0.989 & 0.06 \\
\hline Females & 1.069 & 0.993 & 1.152 & 0.13 \\
\hline Biologics use & 1.166 & 0.981 & 1.385 & 0.13 \\
\hline COPD & 1.041 & 0.954 & 1.136 & 0.43 \\
\hline MI & 1.013 & 0.783 & 1.309 & 0.94 \\
\hline Immunomodulators use & 1.005 & 0.854 & 1.183 & 0.95 \\
\hline
\end{tabular}

UC, ulcerative colitis; 5-ASA, 5-Acetylsalicylic acid.

${ }^{a}$ Subsequent flares were adjusted for as a time varying covariate in the survival model.

${ }^{\mathrm{b}}$ False discovery rate (FDR) adjusted $P$-value. 